\section{Strengthening America's Energy Security with Offshore Wind}

Offshore wind energy is a clean, domestic, renewable resource that can help the United States meet its critical energy, environmental, and economic challenges. By generating electricity from offshore wind turbines, the nation can reduce its greenhouse gas emissions, diversify its energy supply, provide cost-competitive electricity to key coastal regions, and help revitalize key sectors of its economy, including manufacturing. However, realizing these benefits will require overcoming key barriers to the development and deployment of offshore wind technology, including its relatively high cost of energy, technical challenges surrounding installation and grid interconnection, and the untested permitting processes governing deployment.

The United States has immense offshore wind energy resources due to strong, consistent winds off the lengthy U.S. coastline. Data for U.S. coastal and Great Lakes waters indicate that the technical offshore wind resource potential is more than 4,000 gigawatts $(\mathrm{GW}) .{ }^{1}$ When restrictions due to competing uses and environmentally sensitive areas are taken into consideration, offshore wind could still supply the nation with 2,400 GW of capacity - more than double the combined generating capacity of all U.S. electric power plants. For the nearer term, the U.S. Department of Energy's (DOE's) 2008 report 20\% Wind Energy by 2030 envisioned that, under a scenario in which wind energy would supply $20 \%$ of all U.S. electricity, offshore wind could provide $54 \mathrm{GW}$ of generating capacity and $4 \%$ of the nation's total electricity.

\section{Benefits}

Offshore wind energy is both renewable (it cannot be depleted) and clean (it does not emit greenhouse gases or other air pollutants). Wind turbines installed off the nation's coasts and in the Great Lakes can harness the power of offshore winds to generate cost-competitive electricity for homes and businesses in regions with high energy costs. Offshore wind resources are located in close proximity to major cities with high demand for electricity, so harnessing offshore wind power reduces the need to build new transmission lines that serve these cities. A robust U.S. offshore wind industry could generate tens of thousands of jobs and billions of dollars of economic activity. Much of this activity would be concentrated in economically depressed ports and shipyards, which could be repurposed to manufacture and install offshore wind turbines and equipment. 1 Calculated from the total offshore area within 50 nautical miles of shore, in areas where average
annual wind speeds are at least 7 meters per second (approximately 16 miles per hour) at a height of 90 meters (295 feet).

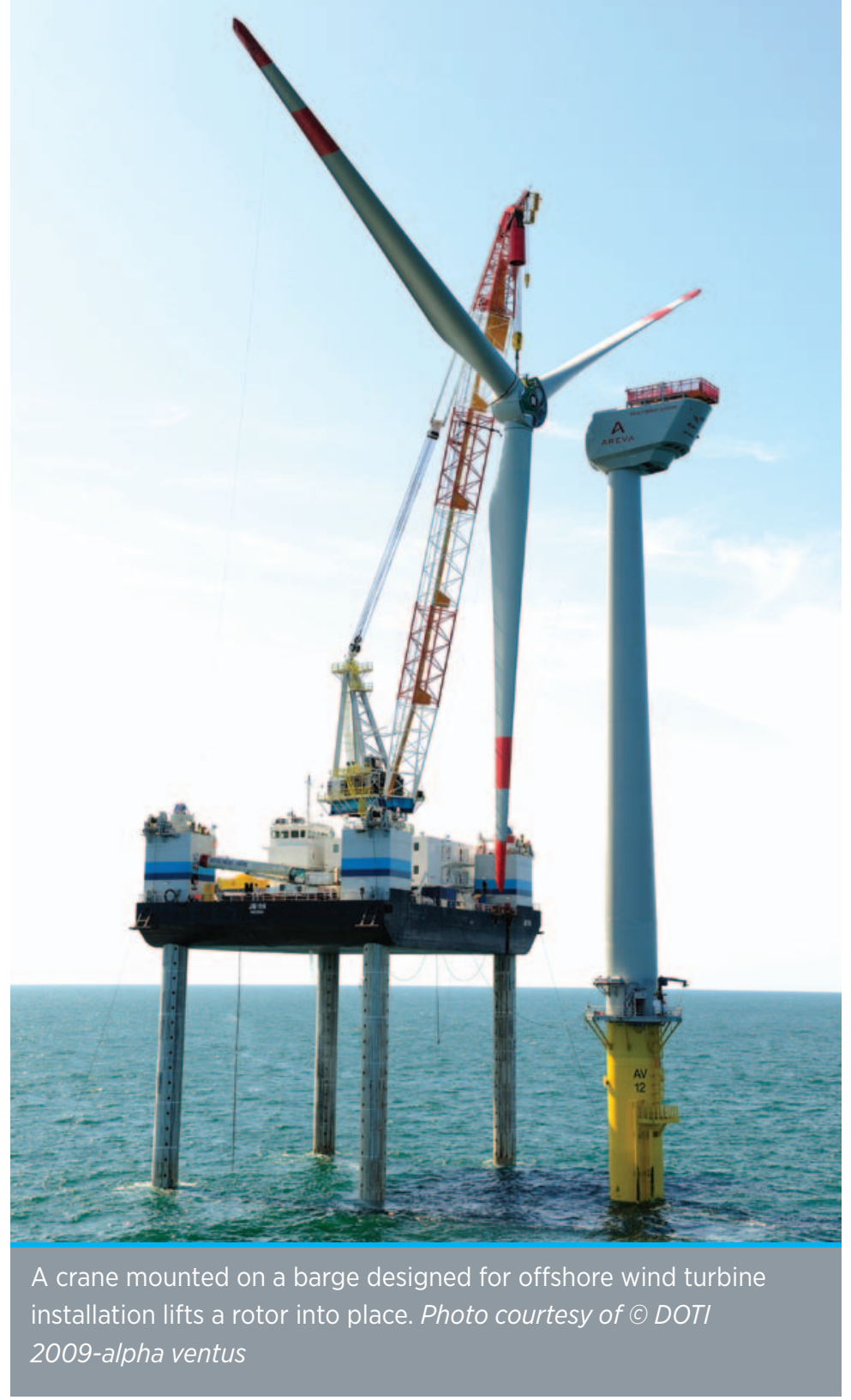

\section{Barriers}

Although the United States has more wind turbine generating capacity installed on land than any other country, there are currently no offshore wind turbines installed in U.S. waters. The vast majority of current offshore wind projects are in Europe, where more than $3 \mathrm{GW}$ of capacity has been installed through more than 53 projects. Project developers have proposed building substantial amounts of offshore wind energy capacity in U.S. waters, most notably off the Atlantic coast and in the Great Lakes.

The major barriers to deployment of offshore wind power in U.S. waters are the high costs of offshore wind facilities; technical challenges surrounding installation and grid interconnection; and the long and uncertain permitting processes 
governing deployment. Offshore wind installations have higher capital costs than land-based installations per unit of generating capacity, largely because of turbine upgrades required for operation at sea and increased costs related to turbine foundations, undersea transmission lines, and installation. Cost-effective installation of offshore wind turbines currently requires portside infrastructure built to fabricate and transport offshore wind foundations and other structures, as well as specialized installation vessels. The infrastructure and specialized vessels do not currently exist in the United States. Finally, potential project developers and financiers face lengthy, uncertain permitting timeframes and requirements that substantially increase the financial risk of offshore wind projects. Estimates for project approvals to build on the Outer Continental Shelf range from 7 to 10 years, longer than for most other types of energy production facilities.

\section{Department of Energy Activities}

To ensure the responsible development of offshore wind energy in the United States, the DOE Wind and Water Power Program is coordinating with federal and state agencies, industry, academia, the public, and other stakeholders to develop a strategy with two objectives: reduce the cost of offshore wind energy to ensure cost-competitiveness with other electrical generation sources, and reduce the timelines and uncertainties associated with U.S. offshore wind project development.

A world-class U.S. offshore wind industry will require a focus on the following collaborative research, development, and demonstration activities:

- Technology Development activities focus on improving offshore wind turbine technology, including system designs, individual components, platforms, foundations, design tools, and design models. Such efforts will lower the cost of offshore wind energy, reduce technological risk, and increase access to deepwater wind resources.
- Market Barrier Removal activities focus on reducing the risks and barriers currently hampering offshore wind power development. Specific activities include efforts to more accurately characterize offshore wind resources to facilitate marine spatial planning; interagency collaboration to close knowledge gaps in the siting of offshore projects; and research on complementary infrastructure needed for the fabrication, installation, interconnection, and maintenance of offshore wind turbines.

- Advanced Technology Demonstration efforts support research, engineering, and planning activities related to the deployment of pioneering offshore wind energy projects. Government and industry collaboration and coordination can accelerate deployment of demonstration projects and subsequently help to validate construction and operations costs, reduce uncertainty, and mitigate risk. In 2012, DOE released a solicitation for the development and deployment of advanced technology demonstration projects, which will generate up to $50 \mathrm{MW}$ of power in multiple U.S. sites.

\begin{tabular}{|l|c|c|c|}
\hline $\begin{array}{c}\text { R\&D } \\
\text { Activity }\end{array}$ & $\begin{array}{c}\text { Amount of } \\
\text { Funding* }\end{array}$ & $\begin{array}{c}\text { Number } \\
\text { of Funded } \\
\text { Projects }\end{array}$ & Timeframe \\
\hline $\begin{array}{l}\text { Technology } \\
\text { Development }\end{array}$ & 26.5M & 19 & $2011-2015$ \\
\hline $\begin{array}{l}\text { Market } \\
\text { Barrier } \\
\text { Removal }\end{array}$ & $16.5 \mathrm{M}$ & 22 & $2011-2013$ \\
\hline $\begin{array}{l}\text { Advanced } \\
\text { Technology }\end{array}$ & 180M & Up to 6 & $2012-2019$ \\
\hline
\end{tabular}

*subject to congressional appropriation

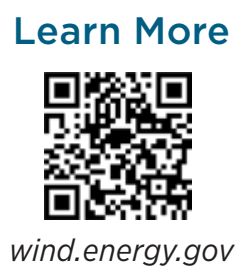

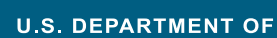
ENAROY

Energy Efficiency \& Renewable Energy
For more information, visit: www.wind.energy.gov 